\title{
Identifying Effective Organizational Factors on Corporate Entrepreneurship in Tehran Municipality's Department of Urban Services
}

\author{
*Peyman Pournasr Khakbaz, Reza Mohammad kazemi, Behrouz Zarei \\ Faculty of Entrepreneurship, Tehran University, Iran \\ *p.pournasr@yahoo.com
}

\begin{abstract}
: the companies have realized the need for entrepreneurship and the entrepreneurial thoughts have penetrated in the administrative structures, because the growth, dynamics and survival of the modern organizations depends on the implementation of organizational entrepreneurship. Consequently, nowadays most of the organizations need organizational entrepreneurship development for growth and survival. The objective of the present paper is to fill the existing gap in the studies. The method of the research is a mixed one; in the qualitative stage, semi-structured and open interviews and investigation of related documents were used, and in the quantitative stage, the questionnaire was applied to gather data. In the research's quantitative stage, a statistical population consisted of managers, employees of the case study were considered, and the simple random sampling method was used. In addition, in this stage, the questionnaires were used as the data collection tool and the experts in the qualitative stage measured the research's validity, and the questionnaire's reliability was approved through Cronbach's alpha of 0.88 . The mean analysis was applied in this stage for the data analysis. The findings of this paper shows that the effective organizational factors in organizational entrepreneurship in Tehran Municipality's Department of Urban Services are categorizes in the seven issues of managerial support, availability of resources, reward systems, corporate culture, entrepreneurial strategies, and risk taking.
\end{abstract}

Key words: effective organizational factors, corporate entrepreneurship

\section{Introduction}

Learning and innovation are essential needs for an organization aiming at survival and effectiveness, and many organizations are intensely looking for innovative and entrepreneurial ways to improve effectiveness, efficiency and flexibility. Therefore, corporate entrepreneurship is rapidly changing into an optional weapon for many of the organizations, especially the large ones. Corporate entrepreneurship is an effort to develop entrepreneurial mentality and skills, and of course, entering these features and mentalities into the corporate culture and activities (Alter, 2006). Most of the organizations are passing from a stable and simple environment to a dynamic and complex one. In such conditions not the growth but the survival of the organizations is at stake. Thus, now most of the organizations need corporate entrepreneurship development to grow and survive. In fact, corporate entrepreneurship is required for the revival and performance upgrade of the companies. Corporate entrepreneurship involves commitment of the company to develop and introduce new products, processes and organizational systems (Light \& Wagner, 2005; Covin \& Slevin, 2011).

With a glance at the presented statistics by Tehran Municipality Research Office, it is evident that the development of corporate entrepreneurship is very crucial for the Tehran Municipality's Department of Urban Services to provide better services and activities. The question is that: how do the organizational factors affect corporate entrepreneurship in Tehran Municipality's Department of Urban Services?

\section{Literature Review}

Theoretical Framework: corporate entrepreneurship generally emphasizes that the corporate entrepreneurship is important and desired for the improvement of entrepreneurial behavior and thinking. Despite the fact, there is a lot literature on corporate entrepreneurship, but it is not clear that how exactly the entrepreneurship is developed and maintained in these organizations. The various present models about the 
realm of the corporate entrepreneurship have shown that there are important individual, corporate, and environmental factors related to corporate entrepreneurial behavior (Covin \& Slovin, 2011). As pointed as the classification of Covin and Slovin of the effective organizational factors covers the effective factors largely, this paper exploited this classification, which includes the seven factors of reward system, availability of resources, risk taking, managerial support, corporate culture, organizational structure, and entrepreneurial strategy. The theoretical framework of the effective organizational factors on corporate entrepreneurship according to the views of Covin \& Slevin (2011) is presented in figure 1.

\section{Figure 1: Theoretical framework}

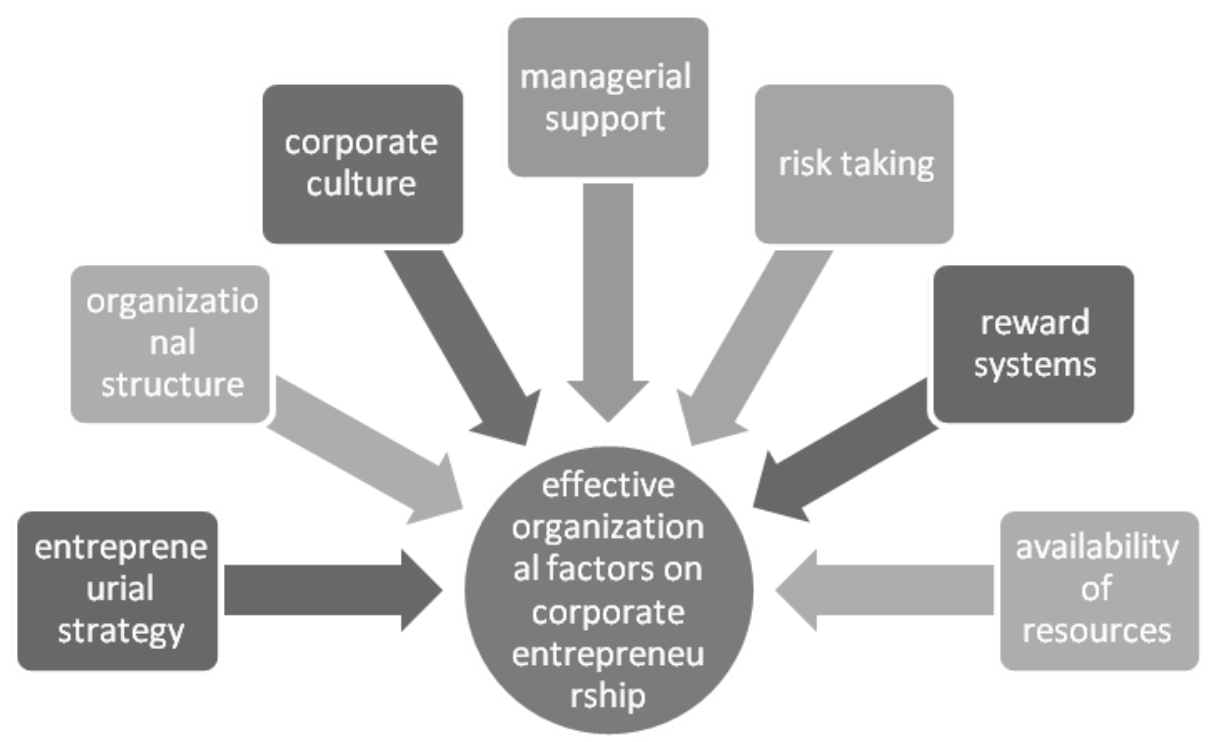

\section{Research Background}

In 1990s and after the researchers carried out many experimental studies to explore the backgrounds of corporate entrepreneurship activities (Padron et al., 2008). The collective findings of these researches show that inter corporate factors particularly play an important role in encouraging corporate entrepreneurship (Andrew, 2003). Although, there is no consensus about what inter corporate factors encourage corporate entrepreneurship (Ana Marı'a \&Murdith, 2007). The researchers aimed at identifying some of the key variables, which affect the corporate entrepreneurship. Sullivan et al (2008) suggest in their paper that organizational variables including structure/formalism, decision making/control, rewards/motivation, culture, risk taking and pre activity in market; and outside elements including politics, complexity, munificence and change influences the ability of the organization in pursuing corporate entrepreneurship. Based on the findings of this research, development of corporate entrepreneurship requires commitment and support of higher managers, organic structure, less formalism, flexible and un-concentrated decision-making, less formal controlling systems, more positive rewards and a higher level of motivation and a flexible and incentive support culture.

Morgan et al. (2008) measured the effect of four corporate entrepreneurship encouraging factors of managerial support, rewarding, independence, and corporate limitations on corporate entrepreneurship capability. Certo and Miller (2008) raise the issue of corporate entrepreneurship development index for evaluating the entrepreneurial activities of the organizations. This paper wants to develop a comprehensive framework to build an entrepreneur organization using elements in all levels of individual, occupational and organizational. Townsend and Hart (2008) testing a sample including 264 employees in medium organizations in their paper suggested three sets of introduction for corporate entrepreneurship: process, field, and individual characteristics. The findings showed that these three factors affect corporate 
entrepreneurship and can trigger corporate entrepreneurship. Johanna and Ignasi (2007) in their paper under the title of " Social entrepreneurship research: A source of explanation, prediction, and delight" examined 223 employees of governmental bureaus. The authors of the paper identified four incentive factors of corporate entrepreneurship: positionchange (the amount of years that takes an employee to be transferred to another section), reward/payment system based on performance, training and trial (the period for acquiring needed skills). The findings show that the most important factor is trial period and then education, reward system and position change respectively. The findings of this paper revealed that practice of internal marketing could have positive effects on nurturing entrepreneurship in governmental sector.

Vanessa (2010) in her dissertation introduces systems, structures, tendency and orientation, trends, people, and culture as obstacles in the way of corporate entrepreneurship. The objective of this research is to enhance the awareness of development and promotion of innovation and entrepreneurial activities of Best Wana organizations. The sample of the research involved 100 employees and the data were collected using questionnaire and random sampling. Then she suggests the following solutions to overcome corporate entrepreneurship obstacles: appropriate organizational atmosphere, attracting and keeping talented and creative people, and creating a suitable balance between innovation and efficiency. These factors, separately and combined together, are important basis for corporate entrepreneurship efforts; as they affect the internal environment of the organization; an environment that determines the tendency and support for entrepreneurial actions. Monika (2008) clearly shows that interorganizational factors affect the type of corporate entrepreneurship activities in an organization. The point is that there is no universal consensus that which of the factors are more important for promoting corporate entrepreneurship activities. Although, it seems that the latest writings on this subject agree on at least seven factors that are provided in table 1.

\section{Table 1: summary of effective organizational factors (Pournasr Khakbaz, 2011)}

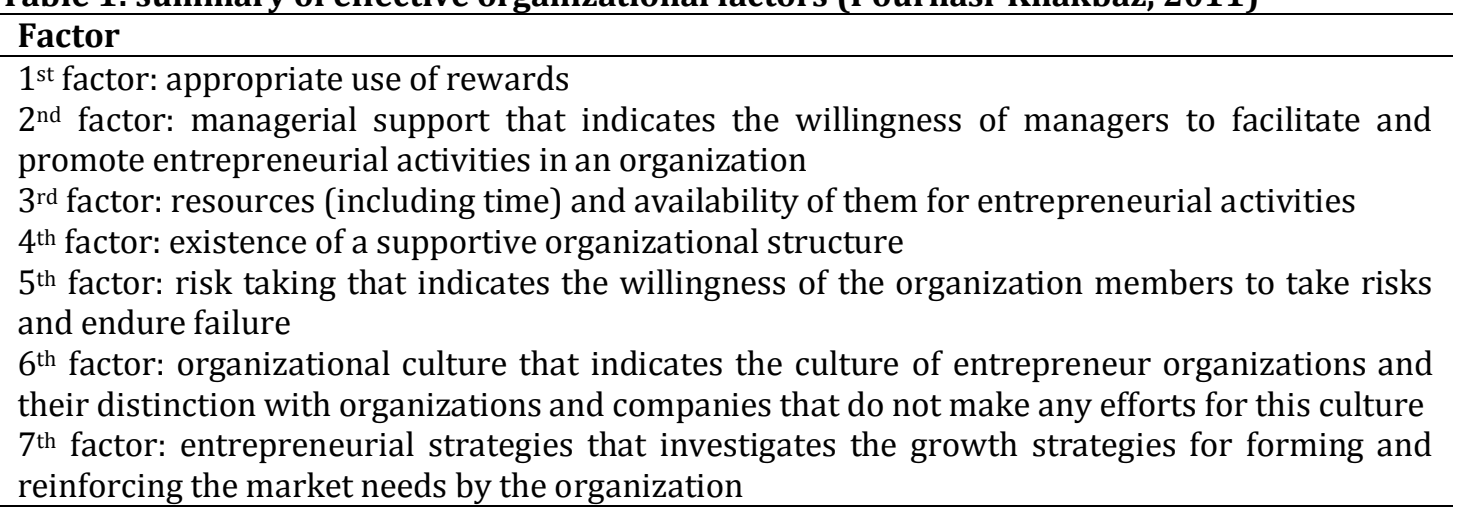

Research Methodology: the paper with respect to goal is an applied study and its research methodology is a combined one. Documentary studies and interviews were used in the qualitative of stage of collecting the data, and in the quantitative stage, questionnaires were used. The statistical population of the study in the qualitative stage was experts and scholars active in corporate entrepreneurship with academic experiences (teaching corporate entrepreneurship for at least 3 terms, having various works about corporate entrepreneurship with at least 3 works) or experiences in consulting or organizations (consulting in the fields of corporate entrepreneurship for organizations or industries) and using purposeful sampling after conducting 19 interviews the data were repeated and in other words collecting the data reached saturation point. In the quantitative stage, the statistical population is a combination of experts and senior managers of the Municipality Organization. For sampling, the Cochran method was used that regarding the population of 250-people, the statistical sample of this paper according to the sample volume estimation formula is limited in the population and it is equal to 81 people. The questionnaires were sent to these people and 79 of them were returned (return rate 0.98 ).

To measure the amount of importance of each one of the dimensions of the questionnaire, the Likert scale was used that has an orderly index and by appointing numbers 1 to 5 to the options, the data were converted 
to quantitative data. The content validity was applied in the study. To measure the content validity we refer to the opinion of 19 people of the experts in the qualitative stage in which the subjects and dimensions were examined and verified. To assess the reliability of the tools the Cronbach Alpha method was used and the amount of Cronbach's alpha that indicates the reliability of the questionnaire was 0.88 that is acceptable as it is larger than 0.60 . This study faced limitations with respect to availability of scholars, and regarding the newness of the study topic, it was difficult to find experts on the subject. On the other hand, there should be more studies to test the findings of this research in different environments and examine its generalization. Study Findings: In the qualitative stage of the research after conducting the interviews, the seven issues according to the theoretical framework including reward systems, managerial support, corporate culture, available resources, organizational structure, entrepreneurial strategies, and risk taking were classified and drawn from the interviews, in the course of the investigations and open and half-structured interviews from the experts and reviewing the documents, the dimensions of the theoretical framework were confirmed, that the frequency of the organizational effective factors on corporate entrepreneurship according to the views of the experts present in the study are shown in table 1.

Figure 2: The frequency of organizational effective factors on corporate entrepreneurship based on the interviews

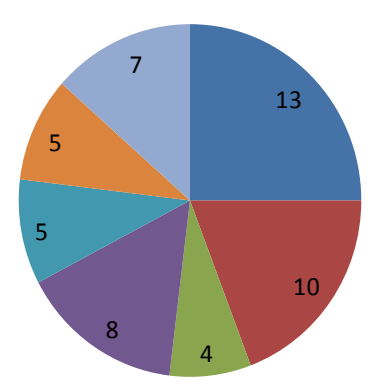

- entrepreneurial strategies

- entrepreneurial culture

managerial support

organizational structures

risk taking

reward systems

availability of resources

In the quantitative stage using mean test and binominal test the resulting components of the qualitative staged were examined. Using mean test the effect of the extracted factors were studied and using binominal test the status of the organizational factors and variables of the corporate entrepreneurship in Tehran Municipality's Department of Urban Services were assessed.

Table 2: Managerial Support Mean Test

\begin{tabular}{|c|c|c|c|c|c|c|}
\hline \multirow[t]{2}{*}{ Row } & \multirow[t]{2}{*}{ Variable } & \multirow[t]{2}{*}{ Mean } & \multirow{2}{*}{$\begin{array}{l}\text { Test } \\
\text { value }\end{array}$} & \multirow{2}{*}{$\begin{array}{c}\text { Test meaning } \\
\text { level }\end{array}$} & \multicolumn{2}{|c|}{ Assurance Distance } \\
\hline & & & & & High & Low \\
\hline 1 & Managerial support & 2.71 & 3 & 0.948 & -0.497 & -0.075 \\
\hline 2 & Available resources & 2.65 & 3 & 0.693 & -0.496 & -0.187 \\
\hline 3 & organizational culture & 2.57 & 3 & 0.818 & -0.603 & -0.239 \\
\hline 4 & Reward system & 2.23 & 3 & 0.779 & -0.942 & -0.545 \\
\hline 5 & Risk taking & 2.52 & 3 & 0.809 & -0.605 & -0.244 \\
\hline 6 & Organizational structure & 2.52 & 3 & 0.809 & -0.605 & -0.244 \\
\hline 7 & Organization strategy & 2.52 & 3 & 0.809 & -0.605 & -0.244 \\
\hline
\end{tabular}


According to the above table, as the resulting mean (2.71) is smaller than test value (3) and also the test meaning level (0.948) is greater than error amount (0.05), thus the $\mathrm{H}_{0}$ theory is rejected and as the assurance distance in the two high domain $(-0.075)$ and low domain $(-0.467)$ is negative, therefore, by a 95 percent confidence we can claim that managerial support, existence of available resources, organizational culture, reward system, risk taking, organizational structure, and organizational strategy are effective organizational factors on corporate entrepreneurship in Tehran Municipality's Department of Urban Services.

The result of two-sentence test of the questions on organizational effective factors on corporate entrepreneurship shows that with a 95 percent about rewarding system it can be said that regular payment in Tehran Municipality's Department of Urban Services is suitable. Job security for the employees and managers in Tehran Municipality's Department of Urban Services is low. Promotions are suitable in Tehran Municipality's Department of Urban Services. Job independence is low in Tehran Municipality's Department of Urban Services. Free time to work on favorite projects is little in Tehran Municipality's Department of Urban Services. Allocating budget for the researches of individuals is little in Tehran Municipality's Department of Urban Services. Participating in conferences is suitable in Tehran Municipality's Department of Urban Services. There is no stock and equity profit, or sharing in the organization and expanded job responsibilities in Tehran Municipality's Department of Urban Services.

About the status of managerial support, it can be said with 95 percent confidence that the managers believe that innovation, as the task of all employees is low in Tehran Municipality's Department of Urban Services. The managers as the facilitators of availability of resources are in a good status in Tehran Municipality's Department of Urban Services. They do not provide the employees with support and defense ideas in Tehran Municipality's Department of Urban Services. They do not pay attention to establish entrepreneurial activities in the procedures and systems. Concerning the organizational culture status, it can be said with a 95 percent confidence that managers do not count on innovation as a source of valuable competition advantage. The managers do not encourage creativity among the members of the organization. They do not encourage looking for innovative opportunities from the outside resources. They do not support creative activities financially. Managers, apart from organizational position, do not share information with the organization members. They do not save a space for an acceptable amount of error for creative ideas when the projects fail. They do not encourage open mindedness towards new ideas and projects. They do not encourage exercising innovations, irrespective of the owners of the ideas including individuals or groups.

About the available resources status, it can be said with a 95 percent confidence that there are no enough financial resources in Tehran Municipality's Department of Urban Services. The managers of the organization do not give over the affairs to the creative and innovative people. They do not provide the employees with sufficient equipment. They take no action to encourage the employees to be innovative. About the organizational structure status, it can be said with a 95 percent confidence thatthere is no organizational structure of administrative mechanisms to assess the ideas in Tehran Municipality's Department of Urban Services. The organizational structure has no mechanism to choose from among the ideas in Tehran Municipality's Department of Urban Services. The organizational structure has no mechanism to exercise the ideas in Tehran Municipality's Department of Urban Services. About the entrepreneurial strategy status, it can be said with a 95 percent confidence that there is no useful organizational content to create entrepreneurial innovations in compiling entrepreneurial strategies in Tehran Municipality's Department of Urban Services. There is no sense of focus of general tendency towards innovative inventions through entrepreneurial perspective. Making sure that the definite innovations will have necessary resources is not seen in compiling entrepreneurial strategies of Tehran Municipality's

Department of Urban Services: About the risk taking status, it can be said with a 95 percent confidence that the organizational environment does not encourage risk taking. Organizational environment does not allow for an acceptable level of failure and err. 


\section{Conclusion}

The findings resulting from different tests concerning the identification of effective organizational factors on corporate entrepreneurship (managerial support, available resources, organizational strategies, organizational structure, risk taking, reward systems, corporate culture) generally indicates that: the findings of the research shows that factors such as: meritocracy, vesting the creative and innovative employees with powers, collaborating with employees in decision makings, which is one the essential managerial components and necessary for corporate entrepreneurship, are weak and do not meet the needs of Tehran Municipality's Department of Urban Services. These findings are compatible with the findings of Brianing (2004) that suggests one of the internal obstacles on the way of corporate entrepreneurship is need for power investment. Hisrich and Peters (2002), Vandenban and Hawkins (2006), and Hamptom and Hampton (2004) found a meaningful relationship between the factors of power investment, supporting innovation and corporate entrepreneurship that confirms the findings of this paper.

No doubt, the managers play an essential role in success of the organizations and they lead the organization; thus having entrepreneurial characteristics is one of the critical factors in the success of the organization. The findings of this paper shows that managers' unwillingness to face challenges, absence of organizational skills among some of the managers, shortage of creative people among the managers are some of the obstacles in the way of corporate entrepreneurship in the organization under study. About the characteristics of managers along with the findings of the investigation of Raynor (2008) and Wong's (2005) findings also confirms the findings of our research. The present research concerning organizational culture is congruent with the explorations of Sidney (2004); Mair and Noboa (2003). They emphasize on the effective and meaningful relationship of organizational culture on corporate entrepreneurship. In addition, the findings of Hornsby et al (2002) on the main and effective factors on corporate entrepreneurship are congruent with the findings of the present paper.

Based on the explorations of Crockett (2005) the organizational structure provides administrative mechanism for evaluating, choosing and implementing the ideas. The structure involves the organizational borders. These borders may be real or imaginary, that can stop or encourage the employees to consider the outside problems of the organization. Therefore, its results are different from the results of this paper, as in the Tehran Municipality's Department of Urban Services organizational structure is only a device to achieve objectives according to the organizational positions, despite the fact that organizational structure is one the effective factors on corporate entrepreneurship. According to the findings of the research, the organizational systems should develop a reward system for such activities and its granting should be based on creative work and its fulfillment. On the contrary, as long as the payment depends on performance it may encourage a behavior based on conveyed role, and may not encourage behaviors related to creative activities and outside the limitations of conveyed role. Therefore, reward system can have a significant effect on entrepreneurial activities. It either can be a tool to increase the said activities or halt it by rewarding other activities.

The third factor is the resources (including time) and their availability for entrepreneurial activities (Covin and Slevin, 2011; Stevenson and Wei-Skillern, 2006). The fourth factor is the existence of a supportive organizational structure (Zahra et al., 1999; Hornsby et al., 2002). Fifth factor is risk taking and indicates failure tolerance (Alter, 2006; Padron et al., 2008).

Research Suggestions: According to the findings of the research and previous studies, the suggestions of the paper resulting from the study and for the use of other researchers is presented here:

- Conducting exploratory studies using other strategies of qualitative research Conducting affirmative studies in the form of organizing researches with the approach of mixed research implementing the findings of this paper in other departments of Municipality and performing contrastive analysis

- Implementing the findings of this paper in the Municipality departments of other provinces

- Conducting research on effective environmental factors on corporate entrepreneurship in Tehran Municipality's Department of Urban Services 
- Conducting research on effective individual factors on corporate entrepreneurship in Tehran Municipality's Department of Urban Services

According to the paper questions, it is suggested that for enhancing the level of corporate entrepreneurship in Tehran Municipality's Department of Urban Services the managers should make their support of corporate entrepreneurship activities stable and not short term. In addition, the reward system should have a suitable status and there should be plans to update them. Finally, it is suggested that there should be plans to promote organizational culture, available resources, organizational structure, entrepreneurial strategy, and risk taking in Municipality Department, such as training courses and familiarity of managers with organizational culture and cutting organizational bureaucracy. It is also suggested that the managers do not depend on organizational factor to promote corporate entrepreneurship level and consider other related factors, too. For this end items such as avoiding rule of morality, honesty, trusting, and believing in organization, increase of commitment and loyalty of members, encouraging the managers to welcome change and opportunity, improving organizational skills of the managers, expanding the need of employees for independence by granting them freedom of action and increasing the risk taking among the managers.

\section{References}

Alter, S. K. (2006). Social enterprise models and their mission and money relationships. In A. Nicholls (Ed.), Social entrepreneurship: New models of sustainable social Change, Oxford, UK: Oxford University Press.

Ana Marı'a, P. \& Murdith, M. L. (2007) Social entrepreneurship: A critical review of the concept. Journal of World Business, 41(5), 564-578.

Andrew, L. (2003). Non-Government Organizational Tool Assessment Social Entrepreneurship. University of Wisconsin Extension.

Brianing, D. S. L. (2004). Creating value throughentrepreneurship: A reconceptualization, theoretical extension, andconceptual level empirical investigation of the resource based view ofthe firm. Ph. Dissertation Abstract. The State University of New Jersey -Newark.

Certo, S. T. \& Miller, T. (2008). Social entrepreneurship: Key issues and concepts. Business Horizons, 51, 267271.

Covin, J. G. \& Slevin, D. P. (2011). A conceptual model of entrepreneurship as firm behavior. Entrepreneurship Theory and practice, 16(1), 7-25.

Crockett, D. R. (2005). The venture management team in corporateentrepreneurship: The role of corporate support and control. PhD Dissertation Abstract. The University of Texas at Arlington.

Hamptom, G. M. \& Hampton, D. L. (2004). Relationship of Professionalism, Rewards, Market Orientation and Job Satisfaction among MedicalProfessionals: The Case of Certified Nurse- Midwives. Journal of BusinessResearch, 57(9), 102- 105.

Hisrich, R. B. \& Peters, M. P. (2002). Entrepreneurship. Tata McGraw- hill publishing company limited.

Hornsby, J. S., Kurakto, D. F. \& Zahra, S. A. (2002). Middle Managers Perception of the Internal Environment for Corporate Entrepreneurship: Assessing a Measurement Scale. Journal of Business Venturing, $17(1), 153-173$.

Johanna, M. \& Ignasi, M. (2007). Social entrepreneurship research: A source of explanation, prediction, and delight. Journal of World Business, 24(2), 169-182.

Juliet, R. \& Cheney, G. (2005). Leadership, learning and human resource management the meanings of social entrepreneurship today. Emerald Group Publishing Limited, 5(3), 1124-1145.

Light, P. C. \& Wagner, R. F. (2005). Searching for social entrepreneurs: who they might be, where they might be found, what they do. Paper prepared for presentation at the annual meetings of the Association for Research on Nonprofit and Voluntary Associations.

Mair, J. \& Noboa, E. (2003). Social entrepreneurship: how intentions to create a social enterprise get formed. Barcelona: IESE Business School Working Paper, 521.

Monika, M. (2008). Intrapreneurship-Way of work in organizations for improvement of working quality. Fifth International Scientific Conference Business and management. 
Morgan, M. P., Munilla, L.S. \& Darroch, J. (2008). Sustainable corporate entrepreneurship. Springer Science + Business Media, LLC, 42(4), 249-252.

Padron, G. T., Hult, G. \& Calantone, R. (2008). Exploiting innovative opportunities in global purchasing: an assessment of ethical climate and relationship performance. Industrial Marketing Management, 37(1), 69-82.

PournasrKhakbaz, P. (2011). Identifying Effective Organizational Factors on Corporate Entrepreneurship in Tehran Municipality's Department of Urban Services. Master thesis. University of Tehran, I.R.Iran.

Raynor, M. E. (2008). Strategic options: A new tool for managing in turbulent environments. 9(1), 21-29, QEmerald Group Publishing Limited, ISSN 1751-5637 Business Strategy Series.

Sidney, S. (2004). Non-parametric statistic for the behavioral science. Translated by Karimi, Y. secondedition. Allame university publication. Tehran, 384 .

Stevenson, A. J. H. \& Wei-Skillern, J. (2006). Social and Commercial Entrepreneurship: Same, Different, or Both? Entrepreneurship theory and practice Review, 23, 305- 324.

Sullivan, M. G., Weerawardena, J. \& Carnegie, K. (2008). Social entrepreneurship: Towards conceptualization. International Journal of Nonprofit and Voluntary Sector Marketing, 8(1), 12-45.

Townsend, D. M. \& Hart, T. A. (2008). Perceived Institutional Ambiguity and the Choice of Organizational Form in Social Entrepreneurial Ventures. Journal of Entrepreneurship Theory and Practice, 8(1), $1042-2587$.

Vanessa, R. (2010). Sport-based entrepreneurship: towards a new theory of entrepreneurship and sport management. International Entrepreneurship management Journal, 22(6), 164-388.

Vandenban, E. W. \& Hawkins, H. S. (2006). Agricultural extension. Translated by tabarraei, M., andzamanipour, A. Ferdousi university publication. Iran-Mashhad. 1st ed. 344.

Wong, K. Y. (2005). Critical success factors for implementing knowledge management in small andmedium enterprises. Industrial Management and Data Systems, 105 (3), 261-79.

Zahra, S. A., Kuratko, D. F. \& Jennings, D. F. (1999). Entrepreneurship and the acquisition of dynamicorganizational capabilities. Entrepreneurship Theory and Practice Journal, 23 (3), 5-10. 